Mohamed Mahmoud A., Hussein Stability of strip footing on sand bed with circular void, pp.1 - 17

\title{
STABILITY OF STRIP FOOTING ON SAND BED WITH CIRCULAR VOID
}

\author{
Mohamed Mahmoud A. Hussein \\ Assistant Prof. Civil Eng. Department, Faculty of Eng., Sohag University, Sohag, Egypt. \\ E-mail:mohamed.ma_2000@yahoo.com
}

Received 28 October 2013; accepted 2 November 2013

\begin{abstract}
Underground voids can be created by different reasons such as tunneling, mining, water and gas networks and old conduits. These voids can cause serious engineering problem leading to instability of the foundation, incurring severe damage to the superstructure. With population growth and resulting extension of urban sprawl to the areas of prior mining cavity such as new cities in Egypt (Menia new city, Assuit new city, Sohag new city and et.,) there is a growth concerning to the geotechnical engineering regarding the foundation stability in these areas. In this paper, numerical investigation of such phenomenon is presented using PLAXIS, 2D software. A series of numerical analysis for strip footing supported on sand bed with an inside circular continuous voids were carried out. The parameters studied in this investigation include the relative density of sand bed (dense sand, medium dense sand and loose sand), the voids embedment depth and voids diameter. The results demonstrate that the bearing capacity of strip footing decreases with the decrease of void embedment depth and vice versa. Also, the bearing capacity decreases with the increase of void diameter. For all sand relative densities, the undesirable structural effects of the void can be eliminated for a void embedded at a depth of around 3.5 times the void's diameter (D). An Equation relating the bearing capacity ratio with the influencing factors investigated is developed. This equation provides a data base useful for design of continuous footing centered with an underground void.
\end{abstract}

Keywords: Strip footing, Sand, Underground void, Finite element, Bearing capacity.

\section{Introduction}

The presence of underground void can cause serious engineering problems leading to instability of the foundation, incurring, severe damage to the super structure. If the void is located just below the footing at shallow depth, the consequence can be very costly and dangerous. Voids may be occurred as a result of mining, tunneling, water and gas networks and old conduits. Besides, the voids can be caused due to tension cracks in unsaturated cohesive soils. With population growth and resulting extension of urban sprawl to the areas of prior mining cavity as new cities in Egypt (Menia, Assuit, Sohage, Qena, et. al), there is growing concern to the geotechnical engineer regarding foundation stability. When faced with the design of foundations above the voids, the geotechnical engineer generally may consider various alternatives such as: (1) to fill the void with acceptable materials, (2) to use piles or caissons to bridge the void and to bear on soil or rock below the bottom of the void; (3) to excavate and found the foundation below the bottom of the void, and (4) to relocate the foundation away from the void. The last alternative of relocation is practicable only if sufficient space is available. Other alternatives are expensive and also are infeasible for the condition with tunnels. To design a stable foundation system above a tunnel, it requires a method of stability analysis for foundation above a void. Such a method is also essential for the economic design of foundations above other types of voids. Studies on the stability of foundations above voids are scarce in the available literature. Only few investigations related to this subject are available. From these studies it has been observed Journal of Engineering Sciences, Assiut University, Faculty of Engineering, Vol. 42, No. 1, January, 2014, E-mail address: jes@aun.edu.eg 
that upon loading, the supporting soil below the footing collapses in the form of a wedge into the void underlying $[9,11,13,14]$. The equations relating the collapse load of strip footing above continuous circular voids in silty clay soil to the void size were developed by using the upper bound theorem of limit analysis [12]. Investigation of the effect of void on footing behavior under eccentric and inclined loads using finite element method was done by authors [14]. They demonstrated that the bearing capacity of footings underlain by central circular voids decreases with increasing load eccentricity and inclined loads. Badie and Wang [2] performed a theoretical and experimental analysis on a model footing above clayey soil to investigate the stability of spread footings situated above a continuous void. The results of this study indicated that there is a critical region under the footing and only when the void is located within this region will the footing performance be significantly affected by the presence of the void. The size of critical region depends on several factors such as footing shape, soil property, void size and void shape. When the void is located within the critical region, the bearing capacity of the footing varies considerably with the void location. Baus and Wang [4] carried out an experimental and numerical analysis to investigate the bearing capacity of continuous footings located above a continuous void in silty clay soil and subjected to static vertical central loads. The test results indicated that there is a critical depth below which the presence of the void has a negligible influence on the footing performance. Also, It was concluded that when the void is located above the critical depth, the bearing capacity of the footing depends greatly on the various factors such as the depth of foundation, the size and location of void. Most of the available studies deal only with footing above continuous voids in cohesive soil (silty clay). Because footings are frequently situated above void in cohesionless soil (sandy soil), understanding the effect of void on bearing capacity of footings performance for this type of soil is equally important. This paper presents results of finite element analysis (FEA) for stability of strip footing above voids in sandy soil. A series of different numerical analysis were performed to evaluate the bearing capacity of strip footing above voids. These analysis were carried out on a prototype model. The finite element analysis is planned to evaluate the role of different factors on the bearing capacity of strip footing such as relative density of the sand, embedded depth of voids (H/B) and voids size (D/B).

\section{Finite-Element Modeling}

The nonlinear behavior of sand was modeled using the hardening soil model, which is an elastoplastic hyperbolic stress-strain model, formulated in the framework of friction hardening plasticity. The foundation was treated as elastic beam elements based on Mindlin's beam theory with significant flexural rigidity $(E I)$ and normal stiffness $(E A)$. A basic feature of the hyperbolic model is the stress dependency of soil stiffness. The limiting state of stress is described by means of the secant Young's modulus $\left(E_{50}^{\text {ref }}\right)$, Poisson's ratio $(v)$, effective cohesion $(c)$, angle of internal friction $(\phi)$ and interface reduction factor $\left(R_{\text {int }}\right)$. A refined mesh was adopted to minimize the effect of mesh dependency on the finite element modeling of cases involving changes of void diameter (D), void embedded depth $(\mathrm{H})$ and relative density of sand bed (Dense sand (D.S), medium dense sand (M.D.S) and loose sand (L.S)). A prescribed footing load was then applied in increments (load control method) accompanied by iterative analysis up to failure. The

Journal of Engineering Sciences, Assiut University, Faculty of Engineering, Vol. 42, No. 1, January, 2014, E-mail address: jes@aun.edu.eg 
Mohamed Mahmoud A., Hussein Stability of strip footing on sand bed with circular void, pp.1 - 17

boundary conditions of the model are taken as follows ( provided with standard fixity option in PLAXIS):

- At the left and right boundary of the soil model,

$$
\begin{aligned}
& u_{x}=0.0, \quad u_{y} \neq 0.0 \\
& u_{x}=u_{y}=0.0 .
\end{aligned}
$$

The analyzed prototype footing geometry, generated mesh, and the boundary conditions are shown in Fig.[1].

Automatic generation of 15 node triangle plane strain elements for the soil, five node beam elements for the footing, an internal angle of friction and secant Young's modulus representing dense, medium dense and loose sand conditions derived from a series of drained triaxial compression tests were used for the sand. Initial stresses in the soil are driven from the material weight $(\gamma)$. In the PLAXIS software, the horizontal stress in static state is calculated using Jacky's formula.

$$
K_{o}=1-\sin \phi
$$

The hyperbolic parameters for the sand were taken from database provided by the software manual, as shown in Table 1.

\section{Table 1.}

Soil Properties used in the Finite Element analysis

\begin{tabular}{|l|c|c|c|c|}
\hline \multicolumn{1}{|c|}{ Parameter } & $\begin{array}{c}\text { Dense Sand } \\
\text { (D.S) } \\
\text { R.D=80\% }\end{array}$ & $\begin{array}{c}\text { Medium Dense } \\
\text { Sand(M.D.S) } \\
\text { R.D=55\% }\end{array}$ & $\begin{array}{c}\text { Loose Sand } \\
\text { (L.S) } \\
\text { R.D =30\% }\end{array}$ & Footing \\
\hline $\begin{array}{l}\text { Secant Youngs Modulus } \\
E_{50}^{r e f}\left(k N / m^{2}\right)\end{array}$ & 40000 & 30000 & 15000 & \\
\hline Cohesion C $\left(\mathrm{kN} / \mathrm{m}^{2}\right)$ & 0.0 & 1.0 & 1.0 & \\
\hline Friction angle $(\phi)$ & 40.0 & 35.0 & 31.5 & \\
\hline $\begin{array}{l}\text { Soil unite weight } \\
(\gamma)\left(\mathrm{kN} / \mathrm{m}^{2}\right)\end{array}$ & 19.1 & 18.15 & 17.44 & \\
\hline Poisson s ratio, $v$ & 0.30 & 0.28 & 0.25 & \\
\hline EA of the footing $(\mathrm{kN} / \mathrm{m})$ & ----- & ----- & ----- & $5 \times 10^{6}$ \\
\hline EI of the footing $\left(\mathrm{kN} / \mathrm{m}^{2} / \mathrm{m}\right)$ & ----- & ----- & ----- & 8500 \\
\hline
\end{tabular}

\begin{tabular}{|c|c|c|c|c|c|}
\hline Group & R.D & $\mathrm{H} / \mathrm{B}$ & $\mathrm{D} / \mathrm{B}$ & Tests No. & Total tests \\
\hline \multirow{7}{*}{ A } & \multirow{7}{*}{$80 \%$} & 0.0 & 0.0 & 1(No Void) & \multirow{7}{*}{29} \\
\hline & & 0.50 & \multirow{6}{*}{$\begin{array}{c}0.25,0.50 \\
0.75,1.0\end{array}$} & 4 & \\
\hline & & 1.0 & & 4 & \\
\hline & & 1.5 & & 4 & \\
\hline & & 2.0 & & 4 & \\
\hline & & 2.5 & & 4 & \\
\hline & & 3.0 & & 4 & \\
\hline
\end{tabular}

\section{Table 2.}

Cases of study

Journal of Engineering Sciences, Assiut University, Faculty of Engineering, Vol. 42, No. 1, January, 2014, E-mail address: jes@aun.edu.eg 
Mohamed Mahmoud A., Hussein Stability of strip footing on sand bed with circular void, pp.1 - 17

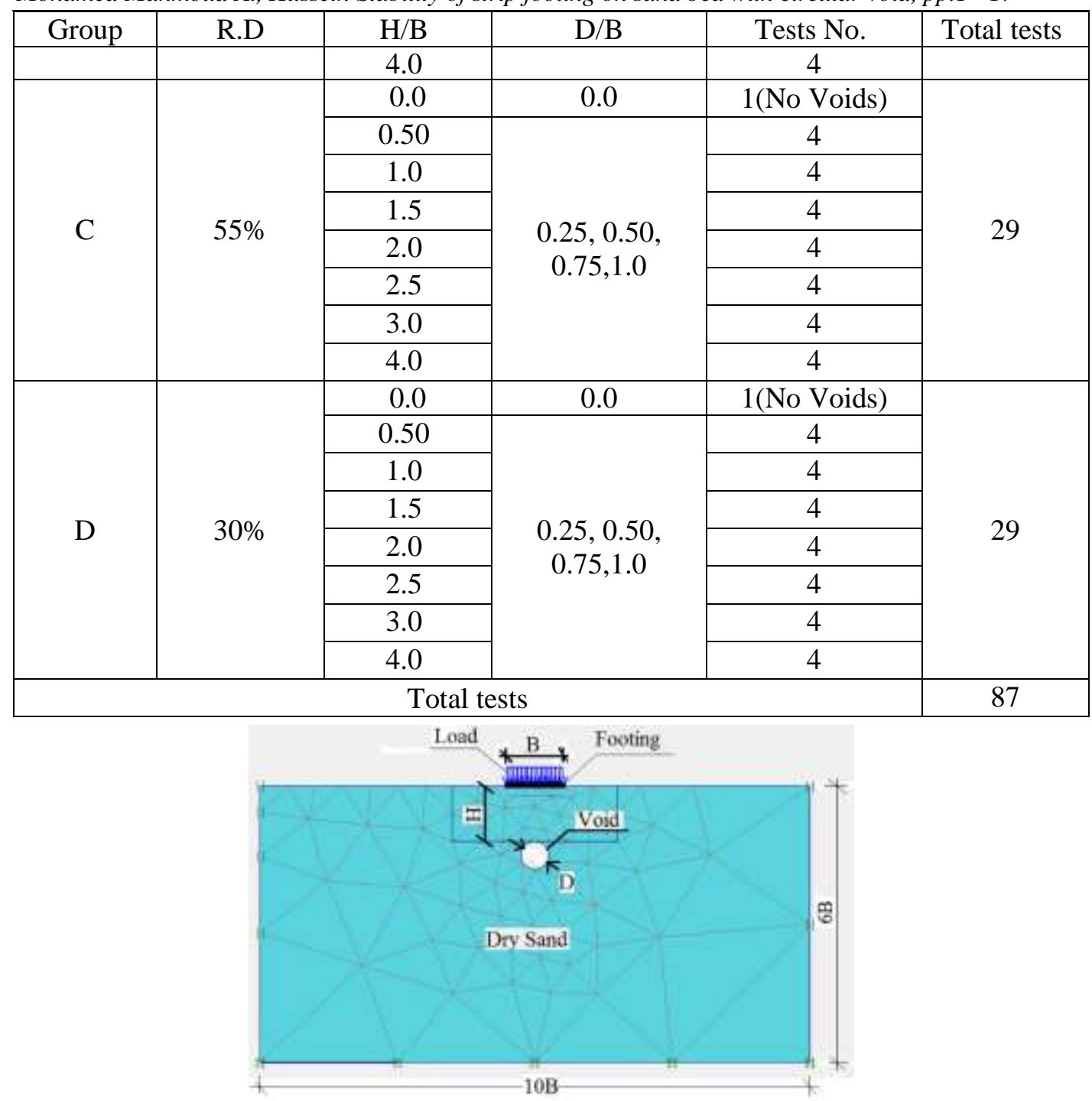

Fig.1. Prototype footing, geometry and boundary conditions

\section{Results and Discussion}

A total of 87 numerical models for strip footing $(B=2.0 \mathrm{~m})$ supported on sand with voids were carried out using PLAXIS, 2D, version 8.2. The effects of void diameter, D, void embedded depth, $\mathrm{H}$ and different relative density of sand bed (R.D $=80 \%, 55 \%$ and $30 \%$ ) on the footing bearing load and settlement were obtained and discussed. The bearing capacity of the footing resting on sand bed with voids is represented using a nondimensional factor, called bearing capacity ratio, BCR. This factor is defined as the ratio of the ultimate footing pressure on sand with voids $q_{u v}$ to the ultimate footing pressure resting on sand without voids $q_{u}$.

Journal of Engineering Sciences, Assiut University, Faculty of Engineering, Vol. 42, No. 1, January, 2014, E-mail address: jes@aun.edu.eg 
Mohamed Mahmoud A., Hussein Stability of strip footing on sand bed with circular void, pp.1 - 17

$$
B C R=\frac{q_{u v}}{q_{u}}=\frac{\text { Ultimate bearing pressure with void }}{\text { Ultimate bearing pressure without void }}
$$

The footing settlement $S$ is also expressed in nondimensional form in terms of the footing width $B$ as the ratio $S / B(\%)$. The ultimate bearing pressures for the footing- soil systems are determined from the load - settlement curves as the pronounced peaks, after which the footing collapses and the load decreases, where this occurs in the general shear failure mode as shown in Fig.(2-a) In curves, which did not exhibit a definite failure point, the ultimate bearing pressure was determined by choosing the footing pressure corresponding to a distinctive marked change in settlement as shown in Fig.(2-b). This method is referred to as the tangent intersection method [9].

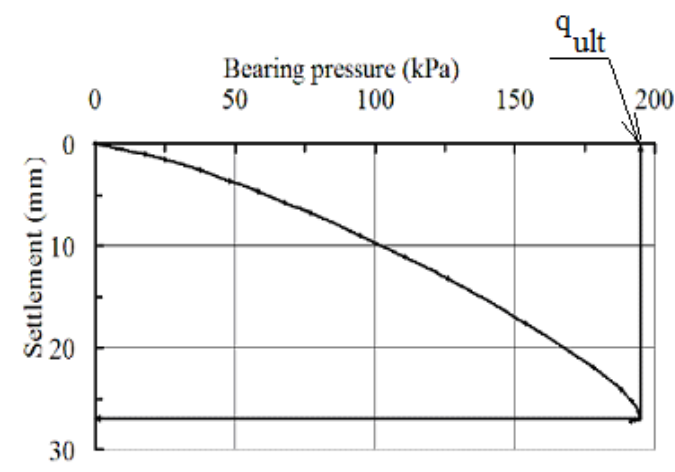

a) For general shear failure

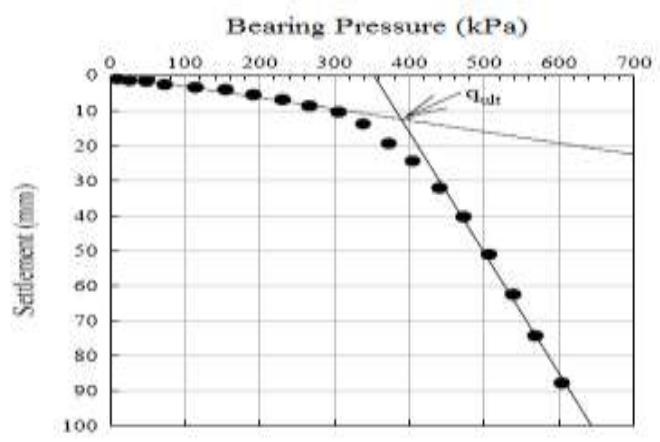

b) Tangent intersection method for local shear failure

Fig.2. Typical bearing pressure-settlement curves

\subsection{Footing-voids interaction in dense sand}

The variation of bearing pressure with settlement ratio, S/B (\%) for strip footing resting on dense sand with continuous circular voids have different diameter ratio $(\mathrm{D} / \mathrm{B})$ and different embedded depth ratio $(\mathrm{H} / \mathrm{B})$ are shown in Figs.[3 a, b, c, d, e, f, g]. From these figures it could be noticed that the bearing pressure decreases with increasing the diameter ratio of voids for any embedded depth ratios. Also, this effect appears noticeably with increasing bearing pressure. It is also apparent that the curves approach to each others with the increase of voids embedded depth. This means that the increase in voids embedded depth leads to an increase in the footing bearing pressure and equals to no void case at $\mathrm{H} / \mathrm{B}$ ranges between 3.0 to 4.0. This result is in a good agreement with that obtained by Moghaddas et. al [6], where they carried out an experimental study of a strip footing on geogridreinforced sand bed above a void and found that with unreinforced sand the critical embedded depth of void ranges around 3.5- 4.0 times the void's diameter with a relative density of $72 \%$. This is obvious because when the voids are located well far from the footing bottom, the soil thickness underneath the footing can accommodate more shear strain before failure. Besides, the arching induced shearing resistance of soil (Terzaghi, 1943). Also, when the void embedded depth increases, the failure is observed at settlements greater than no void case and the failure mode is a general shear failure. This means that the presence of voids in dense sand bed with any diameter and any location has no effect on the failure mode of sand.

Journal of Engineering Sciences, Assiut University, Faculty of Engineering, Vol. 42, No. 1, January, 2014, E-mail address: jes@aun.edu.eg 


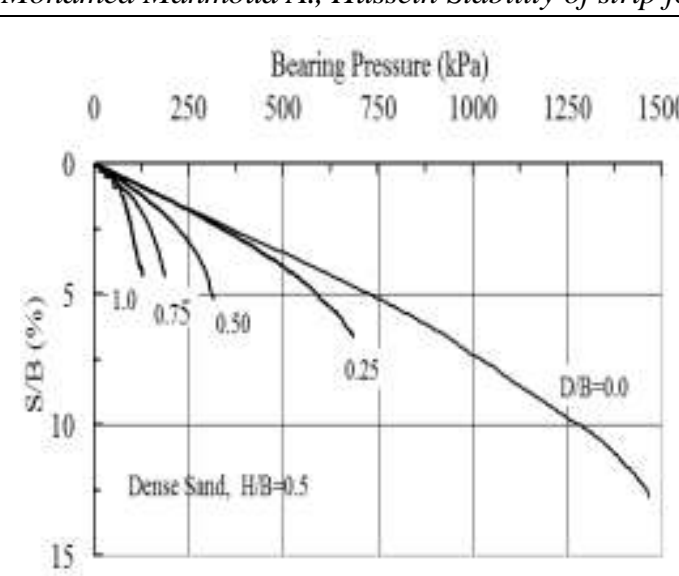

(a)

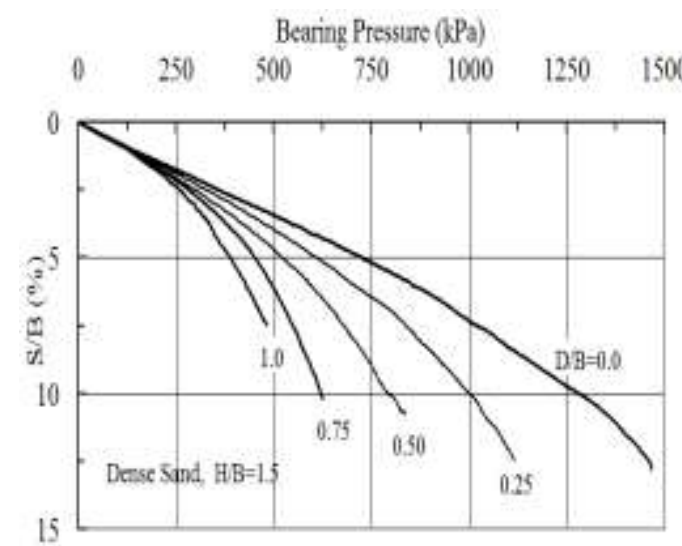

(c)

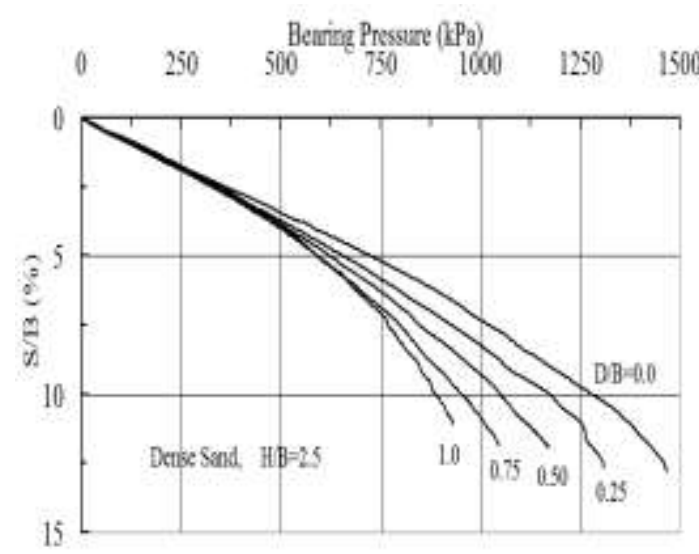

(e)
Bearing Pressure $(\mathrm{kPa})$

$\begin{array}{lllllll}0 & 250 & 500 & 750 & 1000 & 1250 & 1500\end{array}$

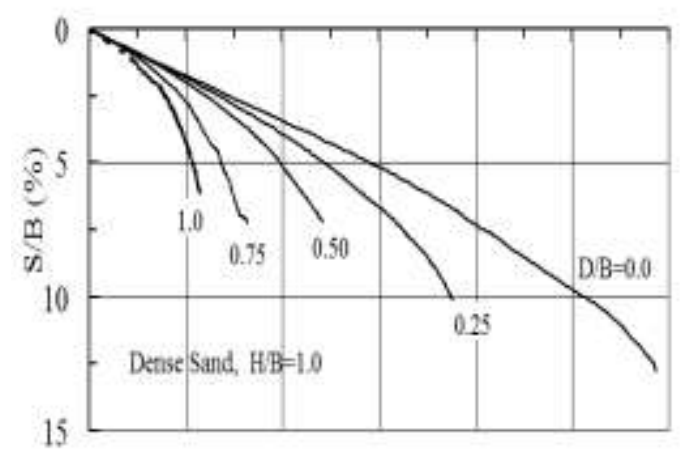

(b)

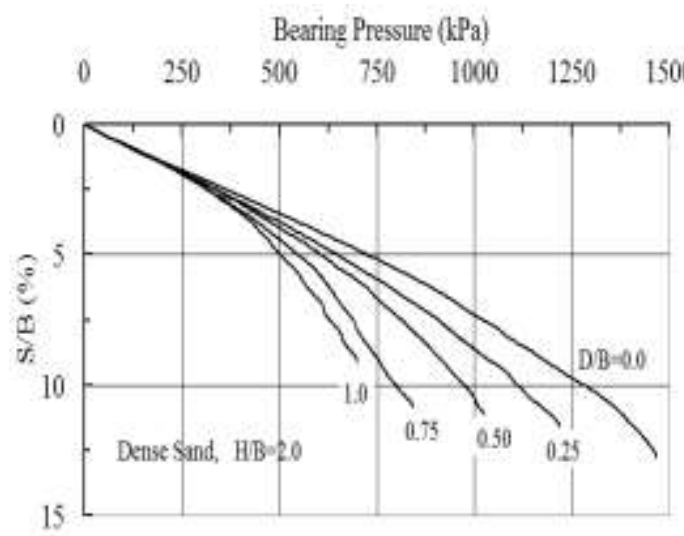

(d)

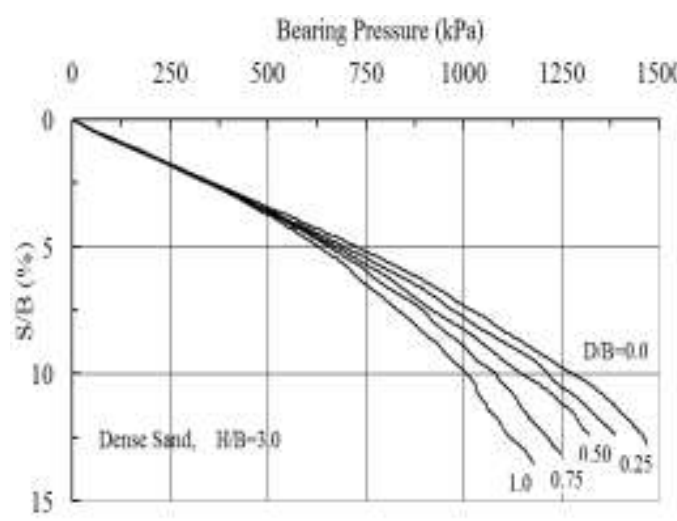

(f)

Journal of Engineering Sciences, Assiut University, Faculty of Engineering, Vol. 42, No. 1, January, 2014,E-mailaddress: jes@aun.edu.eg 
Mohamed Mahmoud A., Hussein Stability of strip footing on sand bed with circular void, pp.1 - 17

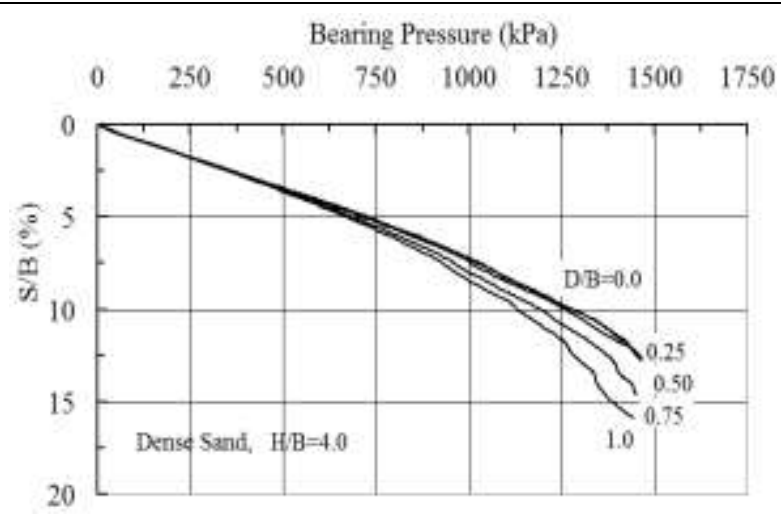

(g)

Fig. 3. Variation of bearing pressure with footing settlement ratio for different embedment depth ratio and void diameter ratio in dense sand

\subsection{Footing-voids interaction in medium dense sand}

The variation of bearing pressure with settlement ratio, S/B (\%) for strip footing resting on medium dense sand bed with continuous circular voids have different diameter ratio and different embedded depth ratio are shown in Figs.[4 a, b, c, d, e, f, g]. From these figures it can be noticed that the bearing pressure decreases with increasing the diameter of voids for any embedded depth ratios. Also, this effect appears noticeably with increasing bearing pressure. It is also, apparent that the curves approach each other with an increase in voids embedded depth. This means that an increase in void embedded depth leads to an increase in the footing bearing pressure and equals to no void case at $\mathrm{H} / \mathrm{B}$ ranges between 3.0 and 4.0 This is obvious because when the void is located well far from the footing bottom, the soil thickness underneath the footing can accommodate more shear strain before failure. Also, when embedded depth of the void increases, the failure is observed at settlements greater than no void case and the failure mode was changed from a general shear failure for cases of no void and for voids with embedded depth ratio, $\mathrm{H} / \mathrm{B} \geq 2.5$ to a local shear failure for voids with embedded depth ratio, $\mathrm{H} / \mathrm{B}<2.5$. This means that the presence of voids in medium dense sand bed at shallow depths changes the failure mode from general shear failure to a local shear failure and the ultimate bearing pressure is determined by tangent intersection method.

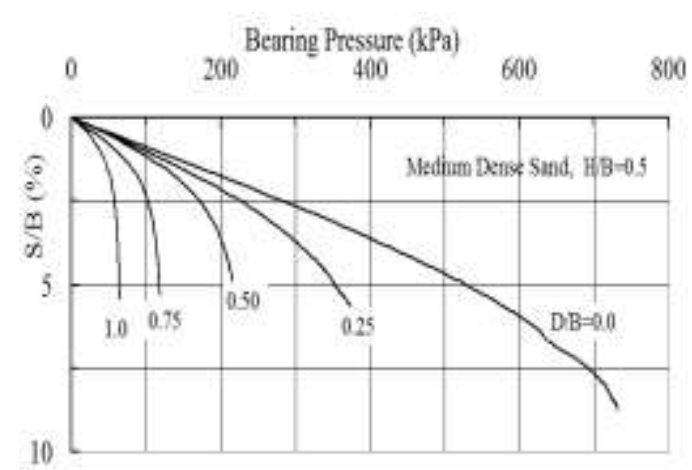

(a)

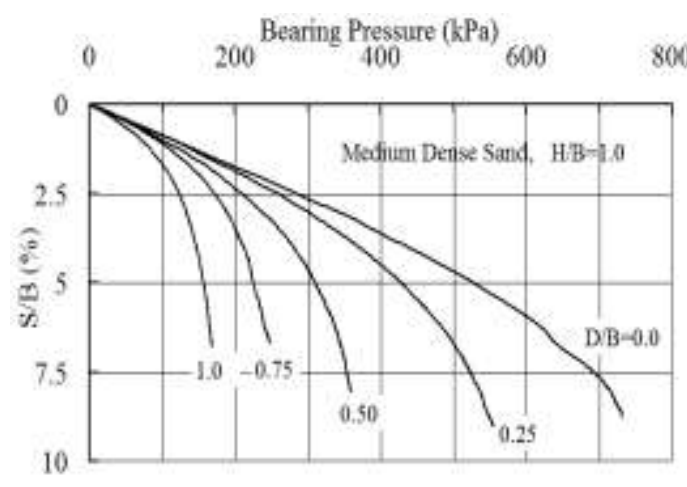

(b)

Journal of Engineering Sciences, Assiut University, Faculty of Engineering, Vol. 42, No. 1, January, 2014, E-mail address: jes@aun.edu.eg 
Mohamed Mahmoud A., Hussein Stability of strip footing on sand bed with circular void, pp.1 - 17

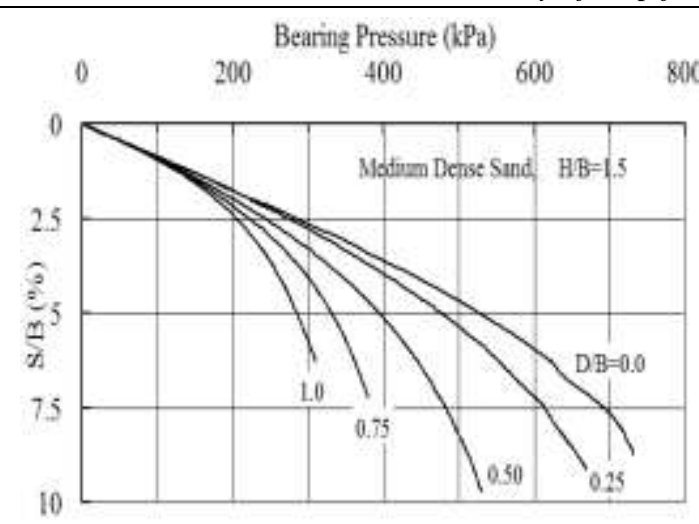

( c)

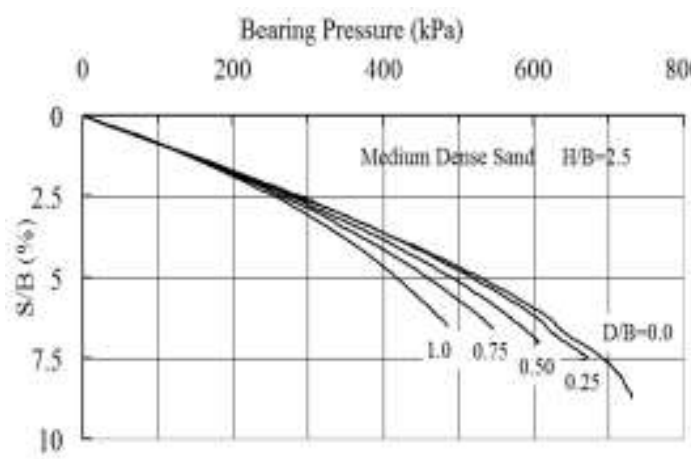

(e)

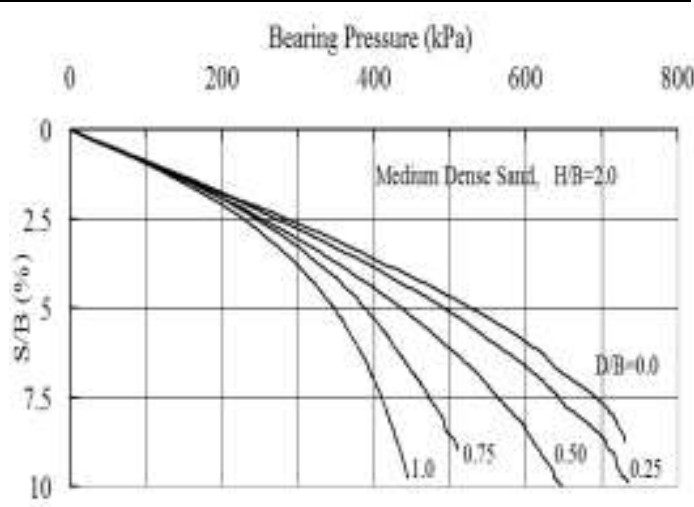

(d)

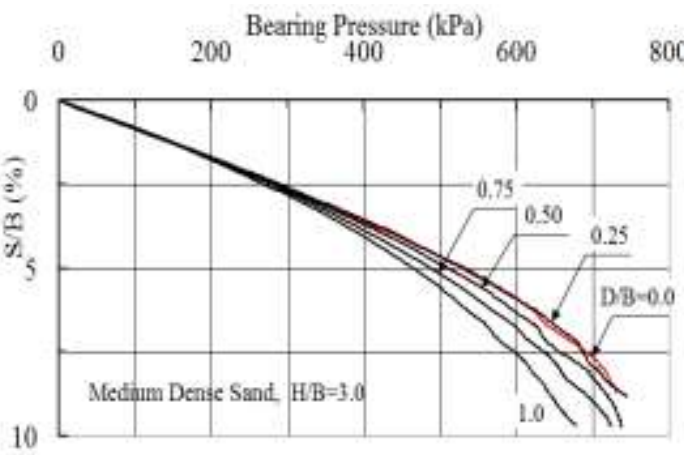

(f)

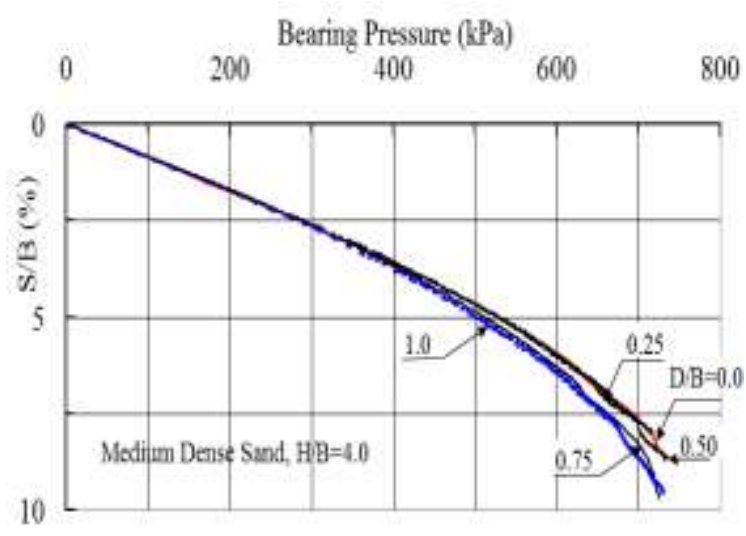

(g)

Fig. 4. Variation of bearing pressure with footing settlement ratio for different embedment depth ratio and void diameter ratio in medium dense sand

\subsection{Footing-voids interaction in loose sand}

The variation of bearing pressure with settlement ratio, S/B (\%) for strip footing resting on loose sand bed with continuous circular voids with different diameter ratios and different embedded depth Journal of Engineering Sciences, Assiut University, Faculty of Engineering, Vol. 42, No. 1, January, 2014, E-mail address: jes@aun.edu.eg 
Mohamed Mahmoud A., Hussein Stability of strip footing on sand bed with circular void, pp.1 - 17

ratios are shown in Figs.[5 a, b, c, d, e, f, g]. From these figures it could be observed that the bearing pressure decreases with increasing diameter of voids for any embedded depth ratio. Also, this effect appears noticeably with increasing bearing pressure. It is also, apparent that the curves approach each other with an increase in embedded depth of the void. This means that an increase in embedded depth of the void leads to an increase in the footing bearing pressure and equal with no void case at $\mathrm{H} / \mathrm{B}$ ranges between 3.0 and 4.0 This is obvious because when the void is located well far from the footing bottom, the soil thickness underneath the footing can accommodate more shear strain before failure. Also, when embedded depth of the void increases, the failure is observed at settlements greater than no void case and the failure mode is a punching shear failure. This means that the presence of voids in loose sand bed with any diameter and any embedded depth has no effect on the failure mode of sand.

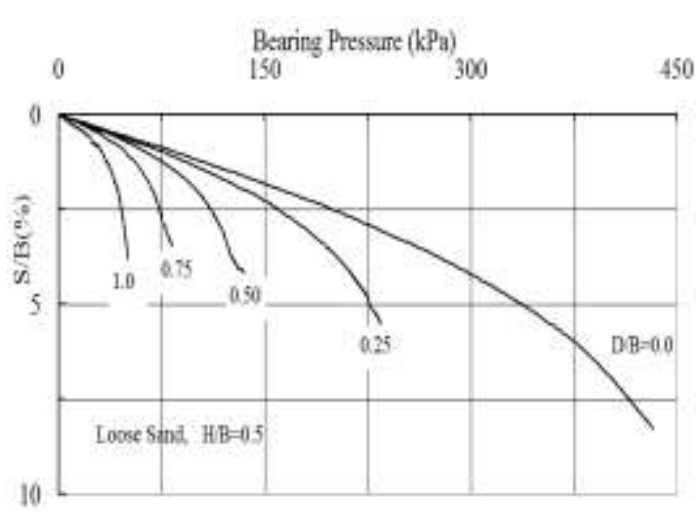

(a)

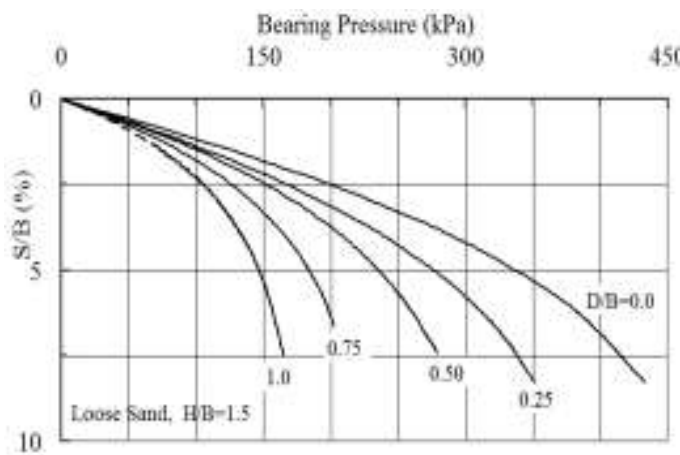

(c)

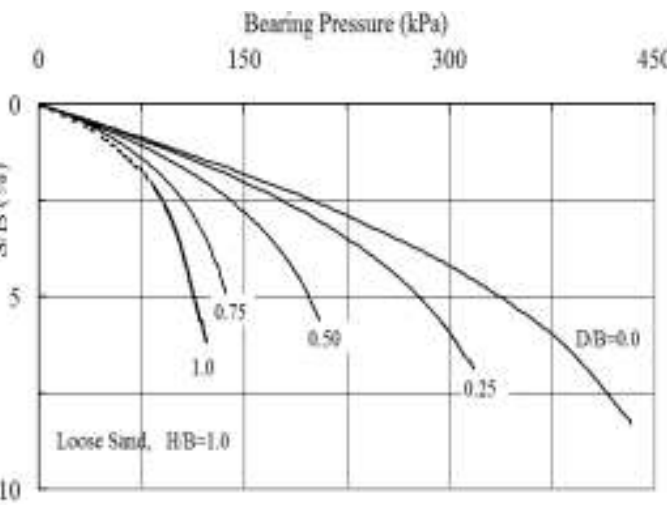

(b)

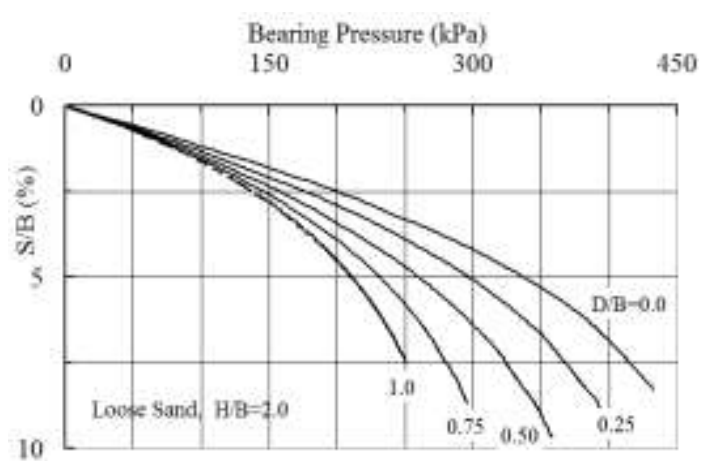

(d)

Journal of Engineering Sciences, Assiut University, Faculty of Engineering, Vol. 42, No. 1, January, 2014,E-mail address: jes@aun.edu.eg 
Mohamed Mahmoud A., Hussein Stability of strip footing on sand bed with circular void, pp.1 - 17

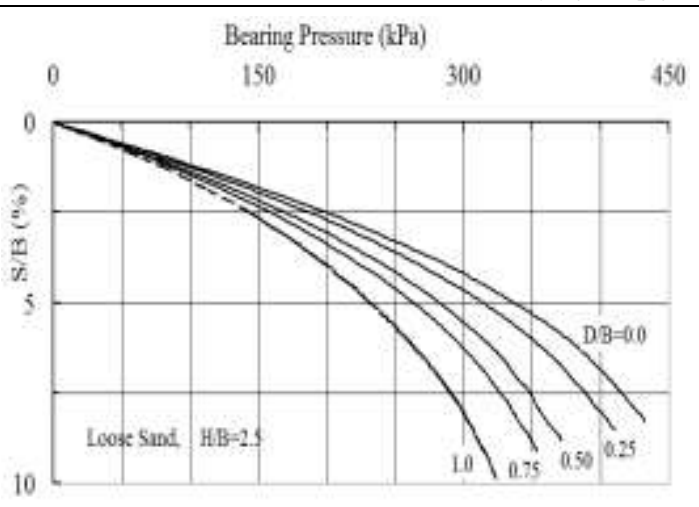

(e)

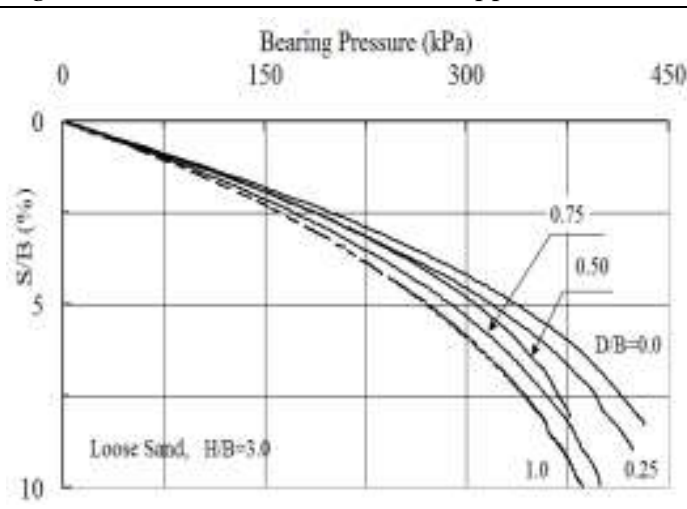

(f)

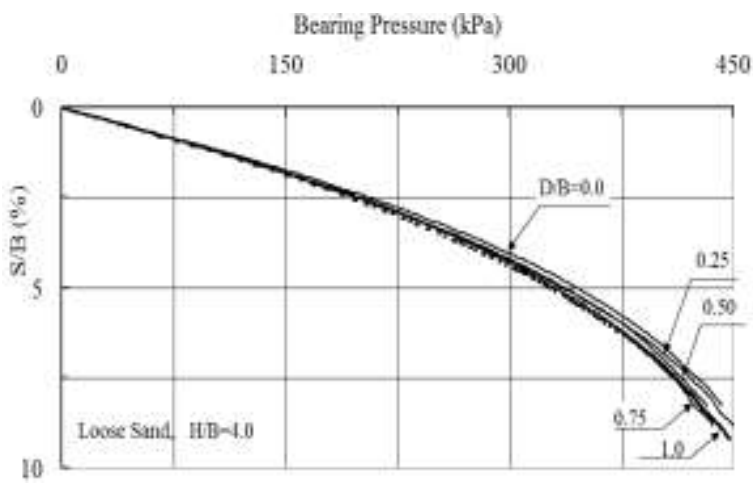

(g)

Fig. 5. Variation of bearing pressure with footing settlement ratio for different embedment depth ratio and void diameter ratio in loose sand

\subsection{Bearing capacity ratio}

\subsubsection{Footing-dense sand-voids model}

A term bearing capacity ratio (BCR) has been introduced to quantify the effect of continuous circular voids on the bearing capacity of surface footing subjected to vertical central loading. The ultimate bearing pressure which obtained from finite element analysis was compared to that obtained from traditional equations by several authors as shown in table [3].

Table 3.

Ultimate bearing pressure by different authors $\left(\phi=40^{\circ}\right)$

\begin{tabular}{|c|c|c|}
\hline Author & $N_{\gamma}$ & $q_{u}=0.5 \gamma B N_{\gamma}(\mathrm{kPa})$ \\
\hline Terzaghi (1943) & 95.61 & 1826.15 \\
\hline Meyerhof (1963) & 93.69 & 1789.48 \\
\hline Hansen (1970) & 79.54 & 1519.21 \\
\hline Vesic (1973) & 109.4 & 2089.54 \\
\hline Present study & 76.7 & 1465 \\
\hline
\end{tabular}

Journal of Engineering Sciences, Assiut University, Faculty of Engineering, Vol. 42, No. 1, January, 2014,E-mail address: jes@aun.edu.eg 
Mohamed Mahmoud A., Hussein Stability of strip footing on sand bed with circular void, pp.1 - 17

The results shown in table [3] indicate that the ultimate bearing pressure obtained in this study is in a good agreement with that obtained from Hansen's equation. The bearing capacity ratio values were obtained from the results of analysis for different void sizes, (D/B) and void locations (H/B) and are shown in table [4].

\section{Table 4.}

Results of footing supported on dense sand with different $(H / B)$ and $(D / B)$ ratios

\begin{tabular}{|c|c|c|c|c|c|c|c|}
\hline $\mathrm{H} / \mathrm{B}$ & 0.5 & 1 & 1.5 & 2 & 2.5 & 3 & 4 \\
\hline $\mathrm{D} / \mathrm{B}$ & \multicolumn{7}{|c|}{ BCR (Dense Sand, $\phi=40^{\circ}, q_{u}=1465 \mathrm{kPa}$ ) } \\
\hline 0 & 1 & 1 & 1 & 1 & 1 & 1 & 1 \\
\hline 0.25 & 0.466 & 0.642191 & 0.761 & 0.8313 & 0.8935 & 0.9488 & 0.996587 \\
\hline 0.5 & 0.214334 & 0.411263 & 0.570375 & 0.69116 & 0.7986 & 0.898976 & 0.993856 \\
\hline 0.75 & 0.126962 & 0.278498 & 0.426314 & 0.5746 & 0.716 & 0.8532 & 0.99112 \\
\hline 1 & 0.086689 & 0.195 & 0.3286 & 0.477 & 0.6375 & 0.809 & 0.9877 \\
\hline
\end{tabular}

A relationship between these values are given in an equation as the following:-

$$
B C R=E X P\left[\left(43.33 \times \phi^{2}-56.1 \times \phi+15.44\right)(-0.4983 \operatorname{Lin}(H / B)+o .6228)(D / B)\right] \leq 1.0
$$

Where:-

$\phi=$ Angle of internal friction of soil (by Radian).

The effectiveness of the developed equation was evaluated by comparing the computed bearing capacity ratio values obtained from this equation with values obtained from the finite element analysis which tabulated in table [4] by plotting these values on graphical relationship as shown in Fig.[6]. It could be observed that there is a good agreement between the two sets of data. It was therefore concluded that the developed equation may become an effective tool for analysis and design of strip surface footing underlain by a continuous circular void in dense sand.

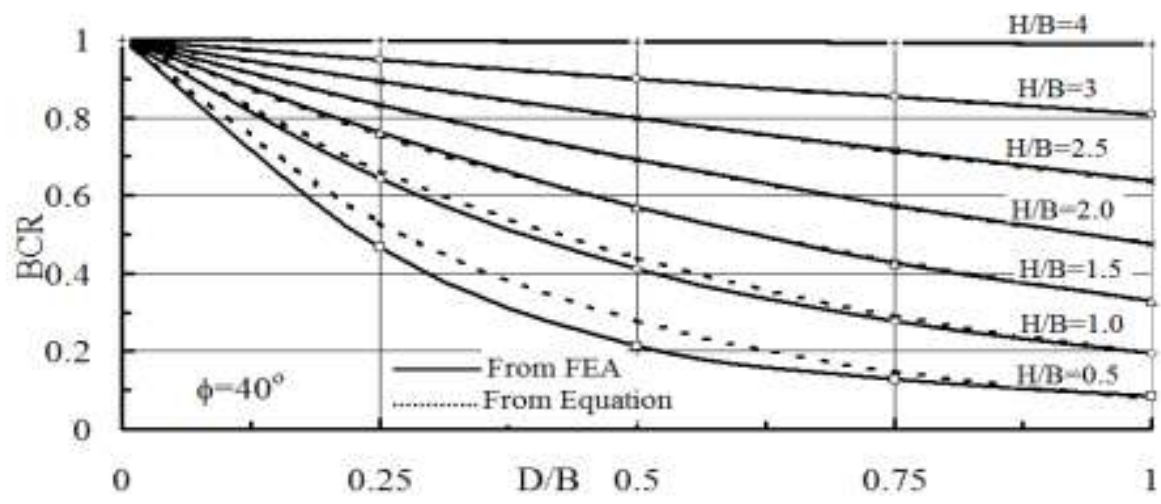

Fig. 6. Variation of BCR with $\mathrm{D} / \mathrm{B}$ at different $\mathrm{H} / \mathrm{B}$ for dense sand

\subsubsection{Footing-medium dense sand-voids model}

The ultimate bearing pressure which obtained from finite element analysis was compared to that obtained from traditional equations by several authors as shown in table [5].

Journal of Engineering Sciences, Assiut University, Faculty of Engineering, Vol. 42, No. 1, January, 2014, E-mail address: jes@aun.edu.eg 
Mohamed Mahmoud A., Hussein Stability of strip footing on sand bed with circular void, pp.1 - 17

\section{Table 5.}

Ultimate bearing pressure by different authors $\left(\phi=35^{\circ}\right)$

\begin{tabular}{|l|c|c|}
\hline \multicolumn{1}{|c|}{ Author } & $N_{\gamma}$ & $q_{u}=0.5 \gamma B N_{\gamma}(\mathrm{kpa})$ \\
\hline Terzaghi (1943) & 41.08 & 745.60 \\
\hline Meyerhof (1963) & 37.15 & 674.27 \\
\hline Hansen (1970) & 33.92 & 615.65 \\
\hline Vesic (1973) & 48.03 & 871.74 \\
\hline Present study & 40.27 & 731 \\
\hline
\end{tabular}

The results shown in table [5] indicate that the ultimate bearing pressure obtained in this study is in a good agreement with that obtained from Terzaghi's equation. The ultimate bearing capacity ratio values which obtained from the results of analysis for different void sizes, (D/B) and void locations (H/B) are shown in table [6].

\section{Table 6.}

Results of footing supported on medium dense sand with different $(\mathrm{H} / \mathrm{B})$ and $(\mathrm{D} / \mathrm{B})$ ratios

\begin{tabular}{|c|c|c|c|c|c|c|c|}
\hline $\mathrm{H} / \mathrm{B}$ & 0.5 & 1 & 1.5 & 2 & 2.5 & 3 & 4 \\
\hline $\mathrm{D} / \mathrm{B}$ & \multicolumn{7}{|c|}{ BCR (Medium dense sand, $\phi=35^{\circ}, q_{u}=731 \mathrm{kPa}$ ) } \\
\hline 0 & 1 & 1 & 1 & 1 & 1 & 1 & 1 \\
\hline 0.25 & 0.522 & 0.659 & 0.7387 & 0.845 & 0.921 & 0.9695 & 1 \\
\hline 0.5 & 0.2648 & 0.43398 & 0.5767 & 0.67852 & 0.834 & 0.9292 & 0.9976 \\
\hline 0.75 & 0.151 & 0.264 & 0.4487 & 0.56 & 0.749 & 0.8948 & 0.9976 \\
\hline 1 & 0.08285 & 0.1947 & 0.30867 & 0.48974 & 0.66347 & 0.8682 & 0.99726 \\
\hline
\end{tabular}

A relationship between these values are given in equation [3]. The effectiveness of the developed equation was evaluated by comparing the computed bearing capacity ratio values obtained from this equation with values obtained from the finite element analysis which tabulated in table [6] by plotting these values on graphical relationship as shown in Fig. [7]. It could be observed that there is a good agreement between the two sets of data. It was therefore concluded that the developed equation may become an effective tool for analysis and design of strip surface footing underlain by a continuous circular void in medium dense sand. 
Mohamed Mahmoud A., Hussein Stability of strip footing on sand bed with circular void, pp.1 - 17

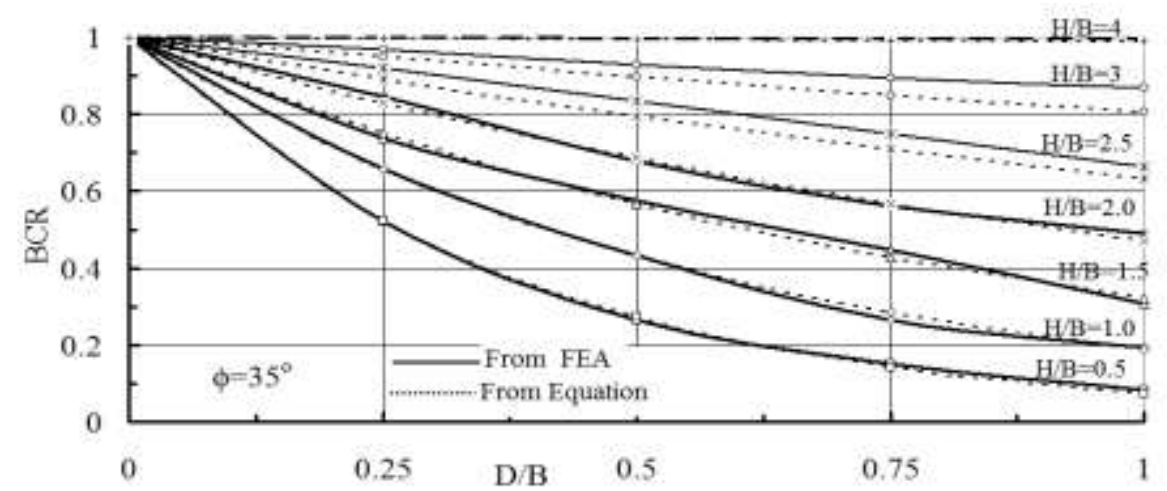

Fig. 7. Variation of BCR with $\mathrm{D} / \mathrm{B}$ at different $\mathrm{H} / \mathrm{B}$ for medium dense sand

\subsubsection{Footing-loose sand-voids model}

The ultimate bearing pressure which obtained from finite element analysis was compared to that obtained from traditional equations by several authors as shown in table [7].

\section{Table 7.}

Ultimate bearing pressure by different authors $\left(\phi=31.5^{\circ}\right)$

\begin{tabular}{|c|c|c|}
\hline Author & $N_{\gamma}$ & $q_{u}=0.5 \gamma B N_{\gamma}(\mathrm{kpa})$ \\
\hline Terzaghi (1943) & 26.15 & 456.056 \\
\hline Meyerhof (1963) & 22.14 & 386.12 \\
\hline Hansen (1970) & 20.725 & 361.44 \\
\hline Vesic (1973) & 22.759 & 396.917 \\
\hline Present study & 19.55 & 341.0 \\
\hline
\end{tabular}

The results shown in table [7] indicate that the ultimate bearing pressure obtained in this study is nearly in a agreement with that obtained from Hansen's equation. The ultimate bearing capacity ratio values were obtained from the results of analysis for different void sizes, (D/B) and void locations (H/B) and shown in table [8].

\section{Table 8.}

Results of footing supported on loose sand with different $(\mathrm{H} / \mathrm{B})$ and $(\mathrm{D} / \mathrm{B})$ ratios

\begin{tabular}{|c|c|c|c|c|c|c|c|}
\hline H/B & 0.5 & 1 & 1.5 & 2 & 2.5 & 3 & 4 \\
\hline D/B & \multicolumn{7}{|c|}{ BCR (Loose sand, $\left.\phi=31.5^{\circ}, q_{u}=341 k P a\right)$} \\
\hline 0 & 1 & 1 & 1 & 1 & 1 & 1 & 1 \\
\hline 0.25 & 0.55835 & 0.72316 & 0.8177 & 0.852 & 0.9237 & 0.9744 & 0.9979 \\
\hline 0.5 & 0.29982 & 0.47302 & 0.6147 & 0.753 & 0.83 & 0.934 & 0.9964 \\
\hline 0.75 & 0.173 & 0.31 & 0.485 & 0.65147 & 0.76 & 0.896 & 0.996 \\
\hline 1 & 0.11964 & 0.25806 & 0.39 & 0.536 & 0.694 & 0.852 & 0.99706 \\
\hline
\end{tabular}

A relationship between these values is given in equation [3]. The effectiveness of the developed equation was evaluated by comparing the computed bearing capacity ratio Journal of Engineering Sciences, Assiut University, Faculty of Engineering, Vol. 42, No. 1, January, 2014, E-mail address: jes@aun.edu.eg 
14

Mohamed Mahmoud A., Hussein Stability of strip footing on sand bed with circular void, pp.1 - 17

values obtained from this equation with that values obtained from the FEA which tabulated in table [6] by plotting these values on graphical relationship as shown in Fig. [8]. It could be observed that there is a good agreement between the two sets of data. It was therefore concluded that the developed equation may become an effective tool for analysis and design of strip surface footing underlain by a continuous circular void in loose sand.

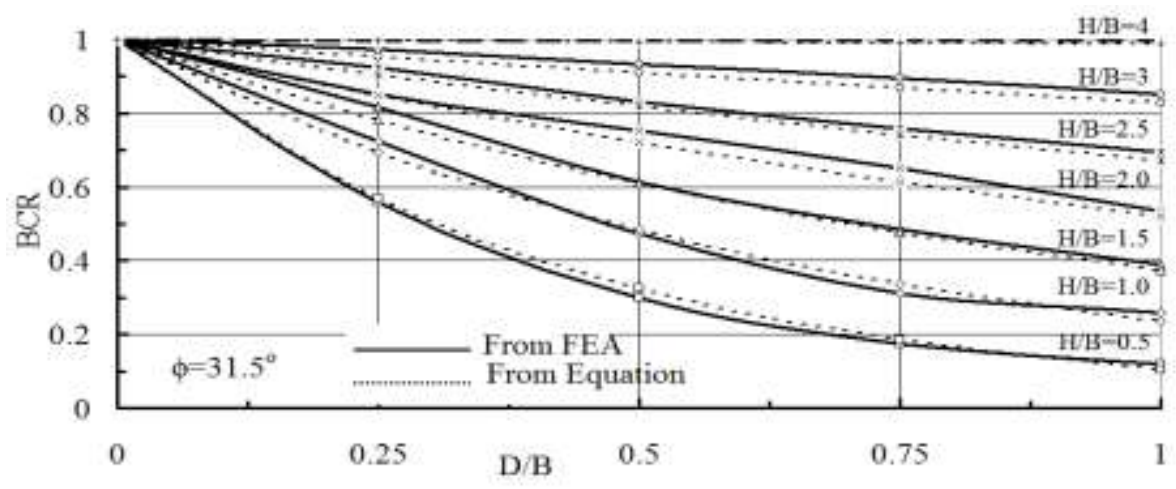

Fig. 8. Variation of BCR with $D / B$ at different $H / B$ for loose sand

\subsection{Effect of sand relative density}

The effect of sand relative density on the bearing capacity ratio (BCR) is shown in Figs. (9 a, b, c, d, e, f, g). From these figures, in general, it can be noticed that the bearing capacity ratio decreases with increasing void size $(\mathrm{D} / \mathrm{B})$ for any relative sand density. The rate of decrease of $\mathrm{BCR}$ is more for $\mathrm{D} / \mathrm{B}<0.75$ and after that the rate is small for $\mathrm{H} / \mathrm{B}$ $\leq 1.0$, and this rate can be considered linear for other cases. Also, from these figures, it can be seen that the three curves are close together despite the difference in the relative density. Therefore, for practical purposes, the relative density of sand has very small effect on the BCR and can be neglected. From the theoretical point of view, if we scrutinize in three curves, we will find that the curve of dense sand is under the curve of medium dense sand and it is under the curve of loose sand. This means that at any void size (D/B) the BCR value increases slightly with decreasing sand relative density. This can be attributed to that in dense sand, the sand layer between the footing base and void is more rigid than that for medium dense sand, which leads to the effect of surface footing load transferred to the void faster than that in medium dense sand and the same trend occurs in medium dense sand relative to loose sand.

Journal of Engineering Sciences, Assiut University, Faculty of Engineering, Vol. 42, No. 1, January, 2014, E-mail address: jes@aun.edu.eg 
Mohamed Mahmoud A., Hussein Stability of strip footing on sand bed with circular void, pp.1 - 17

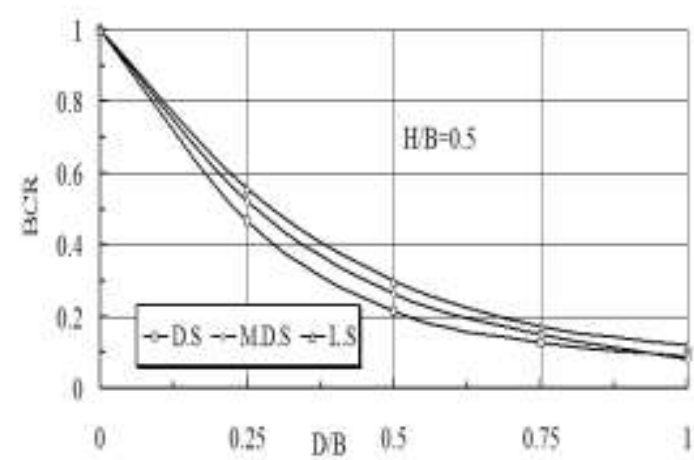

(a)

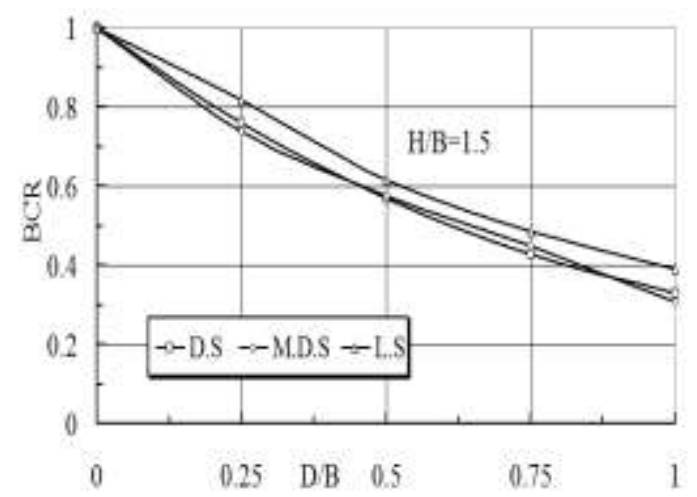

(c)

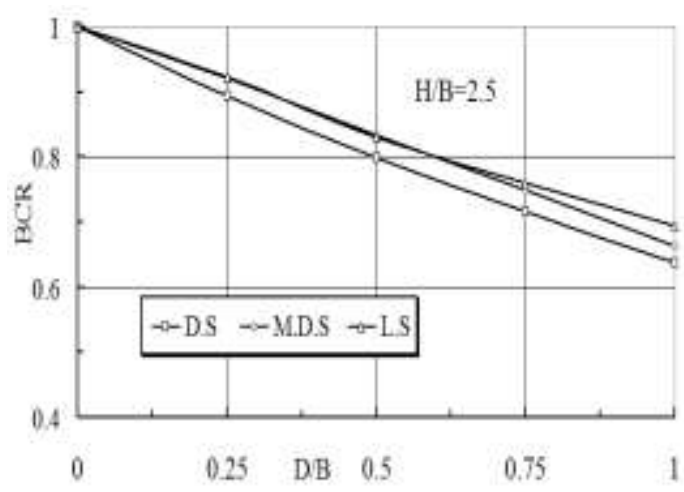

(e)

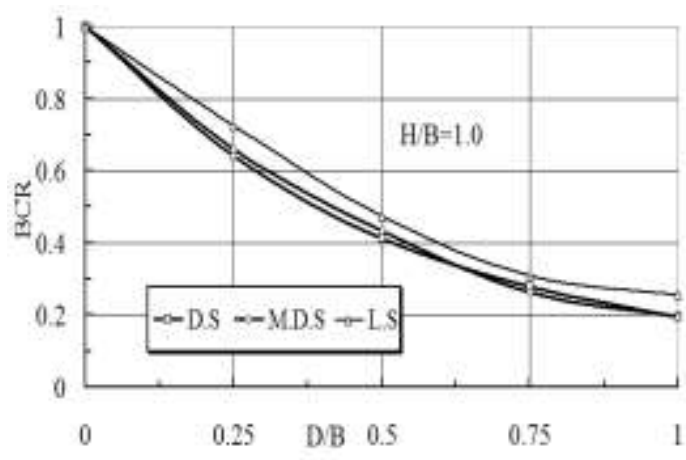

(b)

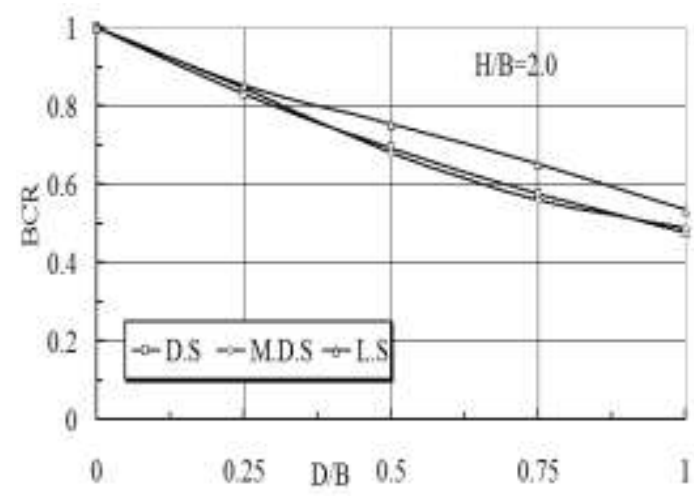

(d)

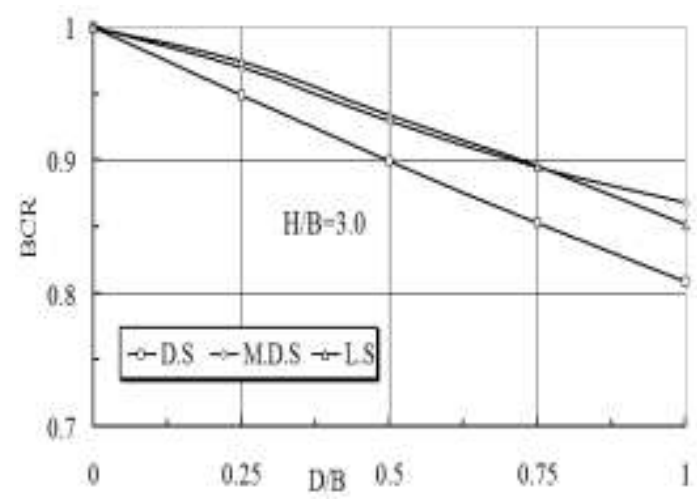

(f)

Journal of Engineering Sciences, Assiut University, Faculty of Engineering, Vol. 42, No. 1, January, 2014, E-mail address: jes@aun.edu.eg 


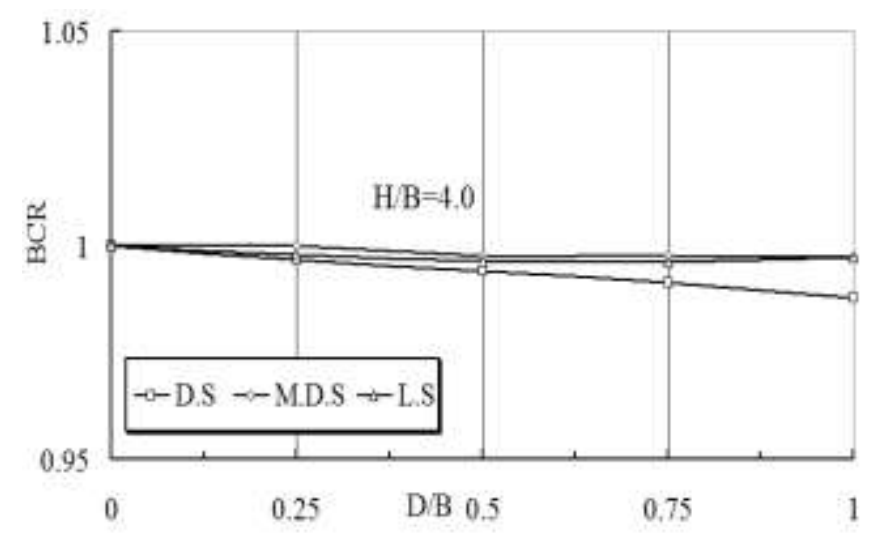

(g)

Fig. 9. BCR Versus $D / B$ for different sand relative density $(H / B=4.0)$

\section{Conclusions}

Numerical analyses for determining the bearing capacity of strip footing constructed on sand bed having voids were performed in this paper using PLAXIS programme. Based on these analyses, it may be concluded that:

1) The existence of void may decrease the bearing capacity of footing. There is a critical region under the footing, only when the void is located within this region, the stability and bearing capacity of the footing will be significantly affected by the presence of the void as the magnitude of this effect must be considered.

2) The degree of void effect on the footing performance depends mainly on void location $(\mathrm{H} / \mathrm{B})$ and void size $(\mathrm{D} / \mathrm{B})$.

3) When the embedment depth of void (H/B) increases, the bearing capacity enhances up to bearing capacity of footing on the sand without void. Thus, the effect of void vanishes when $H / D$ reaches a value which hereinafter is called critical void depth to footing width ratio, $(\mathrm{H} / \mathrm{D})_{\mathrm{cr}}$ and its value equals to about 3.5 .

4) The BCR of shallow foundations in the presence of underground voids is less than in the absence of these voids.

5) The BCR of strip footing constructed on sand bed having a void is a function of both relative density of sand, location of void relative to footing width and size of void relative to footing width and can be calculated from suggested equation No. (3).

6) The effect of voids on the BCR of sand bed is proportional inversely with relative density of sand.

\section{References}

[1] Azam, G., Hsieh, C.W., and Wang, M.C., (1991). "Performance of strip footing on stratifiec soil deposit with void". Journal of Geotechnical Engineering, ASCE 117, 753-771.

[2] Badie, A., and Wang, M.C., (1984). "Stability of spread footings above voids in clay" Journa. of Geotechnical Engineering, ASCE 110, 1591-1605.

[3] Baus R.L. (1978). "The stability of shallow continuous footing located above a void". PhD thesis Pennsylvania State University, at University Park, Pa.

[4] Baus, R.L., and Wang, M.C., (1983). "Bearing capacity of strip footing above void". Journa]

Journal of Engineering Sciences, Assiut University, Faculty of Engineering, Vol. 42, No. 1, January,

2014,E-mail address: jes@aun.edu.eg 
Mohamed Mahmoud A., Hussein Stability of strip footing on sand bed with circular void, pp.1 - 17

of Geotechnical Engineering, ASCE 109, 1-14.

[5] Bringkgreve. R., Vermeer. P., and et., (2002)."PLAXIS-finite element code for soil and rock analysis". Version 8.2, 2D, Plaxis BV. The Netherlands.

[6] Kiyosumi, M., Kusakabe, O., and Ohuchi, M., (2011) "Model tests and analysis of bearing capacity of strip footing on stiff ground with voids" J. Geotech. Geoenviro.Eng., 137(4),363. 375.

[7] Moghaddas Tafreshi, S. N., Khalaj, O., and Halvaee, M.,(2011) "Experimental study of a shallow strip footing on geogrid-reinforced sand bed above a void" Geosynthetics Int. volume 18, Issue 4, Pp. 178-195.

[8] Mostafa El Sawwaf, (2009)"Experimental and numerical study of eccentrically loaded strip footings resting on reinforced sand" Geotech. and Geoenvironmental Eng. Vol.135.No 10. $1509-1517$.

[9] Nabil M. Nagy, (2009)"Numerical investigation of footing width influence on the surface footing-tunnel interaction analysis" $13^{\text {th }}$ Int. Conf. on Aerospace Sciences \&Aviatior Technology, ASAT-13, May 26-28,

[10] Trautmann, C.H. and Kulhawy, F.H., (1988). "Uplift load-displacement behavior of spreac foundations". Journal of Geotechnical Engineering, ASCE, Vol. 114, No. 2, pp. 168-183.

[11] Wang, M.C., and Badie, A., (1985). "Effect of underground void on foundation stability" Journal of Geotechnical Engineering, ASCE 111, 1008-1019.

[12] Wang, M. C. and Hsieh, C. W., (1987) "Collapse load of strip footing above circular void' Journal of Geotechnical Eng, 113, 5: 511-515.

[13] Wang M.C., and Jao M., (1998). "Stability of strip footing above concrete-lined soft grounc tunnels". Journal of Underground Space Technology, Vol. 13, No. 4, pp. 421-434.

[14] Wang, M. C., Yoo C. S. and Hsieh C. W., (1991) "Effect of void on footing behavior unde1 eccentric and inclined loads" Foundation Engineering journal, ASCE, 1226-1239.

[15] Wood, L.A., and Carnach,W.J.,(1985)'"The behavior of footings located above void' Proceedings of the eleventh international conference on soil mechanics and foundation engineering, San Francisco.

\section{دراسة أتزان الأساسات الشريطية المرتكزة على رمل يحتوى على فجوات}

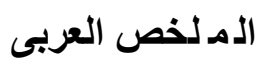

تم أجر اء هذه الدر اسة باستخدام طريقة العناصر المحددة (FEM) باستخدام برنامج البلاكسيس (PLAXIS)

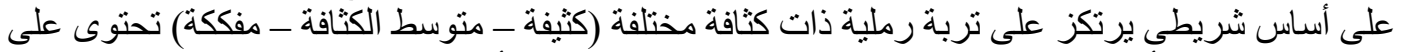

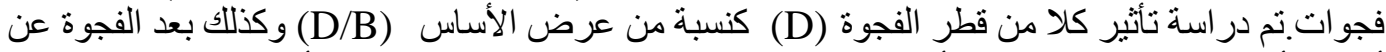

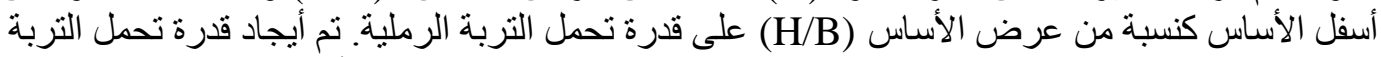

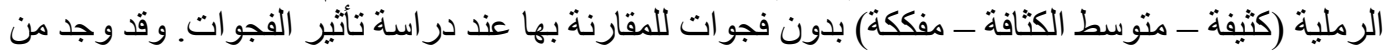

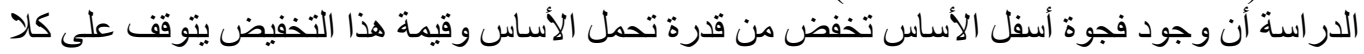

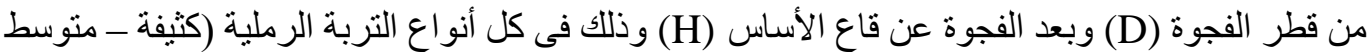

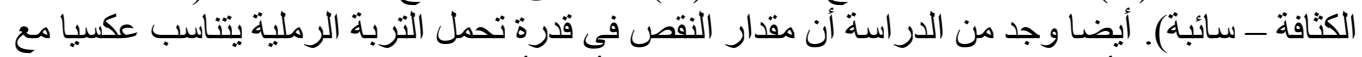

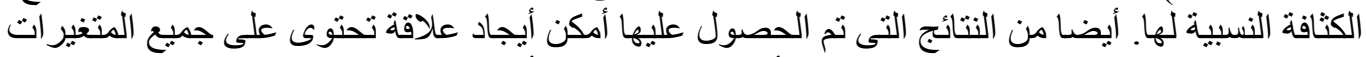

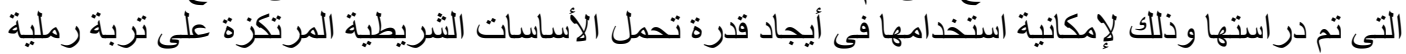
مختلفة الكثافة تحتوى على فجوات فى لصى تصميم الأساسات الثريطية.

Journal of Engineering Sciences, Assiut University, Faculty of Engineering, Vol. 42, No. 1, January, 2014, E-mail address: jes@aun.edu.eg 